\title{
Developmental government for sustainable development and international integration in Vietnam
}

\author{
Minh Phu Nguyen ${ }^{1, *}$ \\ ${ }^{1}$ Vietnam Academy of Social Sciences, no.1, Lieu Giai Str., Hanoi, 10000, Vietnam
}

\begin{abstract}
Developmental government (narrowly understood as a component of a state) is a transparent, effective, efficient government which makes best use of all national resources to create socio-economic development optimistically, actively, innovatively and creatively. Developmental government is not purely a government of integrity without bureaucracy or corruption. More importantly, it plays a role of actively and comprehensively managing its key policies in the market economy to ensure democracy and social equality to bring a fast development to the nation as planned. Hence, developmental government, sustainable development and international integration are inseparable components in the process to build the country in this new development circle. This article focuses to analyze and make clear some issues on Developmental Government and the necessity to establish Developmental Government. Accordingly, the author will propose some suggestions to establish a developmental government suitable to the practicality of Vietnam to meet the requirement of sustainable development and international integration in the current situation
\end{abstract}

\section{Introduction}

"Developmental Government" is a term that has been mentioned here and there in Vietnam recently, not only in scientific fora but also in practical administration management of the State. Therefore, developmental government is a slogan that strongly guides our actions. This term is not a new one and its equivalent ones, "developmental state", "developmental government for improvement" have been commonly used for years.

In general, the international academic community has attained a complete agreement that "developmental state" is a term that has been first used by Charmers Johnson, who uses the term to describe a development model that lies between two economic systems, which are free market capitalist economic system and centrally planned economic system.

Chalmers Johnson proposed his own judgements and assessment on the development state when he studied the marvelous development progress of Japan after the $2^{\text {nd }}$ world war. Japan's development model through fast and modern industrial policies is specifically contradictory to those of the United States and Xoviet Union that time. Beside Japan, some

${ }^{*}$ Corresponding author: nguyenminhphugass@gmail.com 
countries like Korea, Singapore, Thailand, Malaysia etc also started to build their developmental state and have achieved remarkable milestones. How to understand the nature of a developmental government? What are its features compared to a "nondevelopmental state"? Chalmers Johnson when talking about a developmental government has mentioned the following features: (i) It has stable and strong management rules established by the political bureaucratic elite, which helps to create a relatively independent position for that state away from political pressures that might hinder the implementation of the economic policies; (ii) There is cooperation between the private and public sectors (State and enterprises); (iii) The state has invested much in education, healthcare and implemented policies to ensure social equality; (iv) The government is strong, even tyrannic, clear about and good at applying the laws of the market economy"

By that, developmental government has several features. However, it is country independent that the features have certain changes that are not identical in the actual implementation. Singapore is an example for this. The lion's head shaped country began their developmental government by investing in developing their people, building up high quality human resources with enormous budget on education and health care every year (expenses on education alone are $20 \%$ of GDP). The human resources quality has therefore increased incredibly, which is one of the main success factors of Singapore currently.

Generally speaking, developmental government (narrowly understood as a component of a state) is a transparent, effective, efficient government which makes best use of all national resources to create socio-economic development optimistically, actively, innovatively and creatively. Developmental government is not purely a government of integrity without bureaucracy or corruption. More importantly, it plays a role of actively and comprehensively managing its key policies in the market economy to ensure democracy and social equality to bring a fast development to the nation as planned.

Practically, when a country aims for a comprehensive development, it must go with other countries, which requires it to continuously connect, cooperate and widen the network with the outside world under comprehensive management by a proactive and efficient government. That government, moreover, needs to aims for a national development comprehensively in diverse aspects of social life and environmental conservation, not only in economic development. Hence, developmental government, sustainable development and international integration are inseparable components in the process to build the country in this new development circle.

\section{Materials and methods}

The model and method of working are important and decisive in the efficiency and effectiveness of a public authority regime. What to focus here is how to operate a government effectively to meet the more and more increasingly difficult and complicated requirement in the new situation is the solution to the current problems. Nowadays, globalization and international integration are not only a phenomenon but a generalized trend which affects all regions and territories. With such tremendous and quick changes of the environment, a government which stands still without actions or stays conservative will definitely face failures in the near future.

\section{Results}

In Vietnam, in general, the development process has experienced certain ups and downs with difficulties and challenges, which has been proved during 30 years of innovation ("Doi moi"). Vietnam is currently a proactive developing country to attain prosperity, the socio - 
economic environment has been improved, the security - defense system has been maintained. The country has also widened its cooperation with many other countries worldwide and its international stance has been firmed and improved. With current both successes and limitation, it can be asserted that when we have a government of transparency, integrity, innovation, creativeness and efficiency, the objective of drastic and comprehensive development can be met.

On the other hand, to achieve a "legendary" development, we need to have a really strong government. However, whether we can choose something different than a developmental government or this is the only option of government for us, is apparently not an easy decision to make. Theoreticaly and practicaly speaking, there is no perfect model, but depending on environment, resources or context for a government to operate well. A model can be best suited in this environment but less suited in another one, or it may be backward etc. Those are reasons for a developmental government not being a choice for many countries in the world.

However, with the actual conditions of Vietnam, the issue of establishing a developmental government has been proposed for years. It is the fact that since we established our government, we have focused on the objective of development, integrity and for our people. So that, "since the economy of planning, centralization, bureaucracy, and subsidiary was rejected to build a market economy with the management of the State, we have basically followed the regime of a developmental state"

Nowadays, the more obvious requirement of establishing an appropriate developmental government will assist us to precisely refix the role and function of the State in general and the Government in particular in the market economy toward the socialism, by upgrading objectives and solutions of "innovation shade" more drastically and comprehensively.

The official messages of Vietnam on establishing developmental government has been continuously proposed for the past years. Recently, to affirm the determination on a developmental government, Prime Minister Nguyen Xuan Phuc has emphasized: “...We are determined to establish developmental government for our people, enterprises to speed up international integration and continue to execute our goal for a solid macro stabilization, regime and law reform and sustainable development..."

In conclusion, establishment and implementation of appropriate developmental government in our country need to be further affirmed with more upcoming comprehensive steps to meet the requirement of the new situation.

In each period of development, the role and function of the government have certain changes, with the changes of the socio - economic conditions. For instance, the more prosperous the society becomes, the narrower the managing and ruling role of the government is, for the servicing function to be strengthened and improved. Developmental government significantly required this servicing. The role of the government must be adjusted to be correspond to the market regime, where a government takes the leading role to encourage and support rather than penetrate deeply like in the centralized bureaucratic market, but refrains from drifting it without regulation.

Therefore, firstly, to successfully build developmental government, the mindset on the role and function of the government in the new condition needs to change. The government then, while being a servant and supporter of the people and enterprises, needs to be capable of proactively leading and problem solving management by establishing the appropriate and strong enough law and policy system. Stated another way, the role of the government is expressed sufficiently and properly in diverse aspects of a servant, a "fellow" and an administor.

It can be stated that, a more lean, effective and efficient civil authority has always been the objective of many countries. In our country, the organization of State apparatus in general and government in particular is still cumbersome with many layers. The functions, 
responsibilities, rights, organization, internal and external relationship of several bodies do not clearly meet the requirement. On December 30, 2020, the Ministry of Home Affairs held a country-wide online conference on 5 year closing of 2016-2020 and deploying 2021 's plan of the industry where Deputy Prime Miniter, Mr. Truong Hoa Binh attended and had a guiding speech. In the establishment of institution and policy, the Ministry has owned and cooperated with other related ministries to advise to the Politburo, the Secretariat, the Congress, the Government and Prime Minister to promulgate several policies on organization of administration bodies, public non-business units, arrangement of administration units, civil servant and official management, wage policy, belief, religion, emulation, reward and archive to institutionalize the policy by the Party on continuous innovation, create a lean, efficient and effective political apparatus.

In the level of central government, departments and equivalent have reduced 12 in number; bureaus and equivalent have increased 7; general bureaus and equivalent have increased 2; public non-business units have decreased 10; units under general bureaus and equivalent have increased 6; units under Government bodies have decreased 24 in number.

In the level of local authority, specialized units have reduced 5 in number, of which 973 departments units have been reduced; 127 branches have decreased, of which 1,179 departments have been reduced; other administrative units under local People's Committee have reduced 12 in number; public non-business units have reduced 3,819 in number ( $7.33 \%$ equivalent). In the distric level, specialized units have been reduced 294, of which there are 278 departments.

There are "5 reductions", such as contact points, intermediary levels, managers, payroll and administration procedure under the Resolution No. 18-NQ/TW “...issues on continuous innovation, rearrangement of political apparatus to be lean, effective and efficient..." and Resolution No. 19-NQ/TW "...on continuous innovation on organization and administration system, upgrade of quality and effectiveness of public non-business units..." are not apparently efficient as a result of incorporation process is physically dependent without focus on thorough solutions, which in turn has resulted in "blocked up" apparatus organization and still expanded payroll. Therefore, to have a lean apparatus, regulation on organization, operation of administrative apparatus and appropriate government structure should be swiftly completed without overlaps of functions, responsibilities, rights, authority and other business relationship. First and foremost, it is necessary to make clear the regime of assignment, cooperation and mutual control among public units in the process of practices on legislation, execution and justice rights regulated by the law for the functions and responsibilities of law execution to be expressed more clearly. Regarding the organization, strengthening and reorganization the apparatus should be continuously focused, especially online structures to reduce intermediary and deputy levels, connect points in industries such as communication - construction, finance - investment planning, ethnicity - religion etc. Meanwhile, legal regulation needs to be further developed to enhance empowerment and gradation to create activeness and creativeness for the local authority to ensure active administration apparatus in all situations.

During management and enhance of socio-economic development, the Government needs to make drastic kicks with strategic policies. Not only in the slogans and emulation programs, the execution should be done through comprehensive, systematic (other than "term mindset" planning), flexible and sharp plans. The vision of the Government will be expressed in strategies to stay balanced and harmonized among sectors.

Together with reorganizing the policy and development guideline system, another point is to execute planned objectives seriously and drastically as it is more significant to find the way to execute the strategy rather than quickly setting the strategy. The solution should not be fuzzy and the strategy needs to be continuously executed so as it can go beyond "planning stage". Therefore, strategy planning should always sticks with execution 
solutions.

Social trust is a tremendous power for a nation to develop. Therefore, the government needs to upgrade itself on persuasion, trust creation for the people, commit to its people and enterprises and execute the commitments. In the meantime, the Government must create best conditions for its people, enterprises and social organizations to participate in establishing policies and law so that the people and enterprises can see more of their own roles and responsibilities in the community. The ability to contract its people into policy building process is in proportion with the actual value of those policies.

Seen from a higher angle, the society and Government should "travel in the sole boat" toward the mutual development and prosperity target of the country, in which the Government is the captain of the boat. There should be strong two-way trust among Government, its people and enterprises. Stated another way, the Government and the society must have tight and strong cooperation where the Government shares part of its functions to the society to only lead the supervisory role, mainly in certain sectors like public service provision, especially health care, education etc. as the Government is incapable of every part of public services and goods provision. With that incapability, there will be huge disadvantages for both the Government and the society, which worst affects consumers of those services. As a result, for a more efficient Governement, there is necessarily sociliazation to enhance privatization in the selective provision of public services and goods. Accordingly, legal framewok on public service provision needs to be completed, in which public private partnership (PPP) is especially concerned. For instance, "public administrative contract" should be applied in all administration areas of the Government and BOT is one of the examples.

On the other hands, it is essential to have complete legal framework, effective resource allocation, improved investment- business environment, investment attraction into key industries, startup community development promotion, innovation, technology transfer enhancement, application of advanced technonogies into provision of public services, which is highly significant in our gradual joining into the fourth industrial revolution with interleaved chances and challenges in all aspects. Chances of approach and application of technological advances can be seized to create public administration as not only procedure aspect but also tremendous motivation to speed up development process.

Employees, civil servants and officials are key staff for the success of the national administration. When the managing staff have efficient policies and high determination but the executing staff is insufficient and incapable, the policies and determination are then theoretical only. In such a case, whether establishing developmental government can gain success, quick or slow, practical or theoretical will mainly depend on the employees, civil servants and officials. More precisely, the ability to establish developmental government is the ability of employees, civil servants and officials, which is "walk the talk". For that kind of government to be established, each employee, civil servant and official is fully aware of developmental spirit. Not only developmental managing staff but also developmental executing staff are in need. They are neccessarily educated, qualified, with a vision, forecasting and guiding abilities to cope with new arising problems, especially "hot social issues" in timely, precise and thorough manner.

However, the ability of employees, civil servants and official of the development process can be gradually attained and completed during the development process. To upgrade the ability of those staff, it is essential to execute diverse solutions simultaneously, from policies, laws to people and physical conditions that are attached with administration innovation process. For that, the recruitment needs to be improved to select best people with virtues and talents, qualification and abilities suitable with the assigned positions. For instance, significant guidelines and policies on attracting, employing and retaining talents in public administration should be implemented efficiently, like the Conclusion 86-KL/TW 
dated January 24, 2014 by Politburo on attracting and resourcing from excellent graduates and young staff; staff proposing policy and management trainee application etc. Meanwhile, focuses should also be placed on training and fostering employees, civil servants and officials through appropriate programs to ensure real training - real employment, forcibly reject low qualified staff who fail to meet up requirements, responsibilities or with incapability etc.

Apart from Japan, when mentioning about actual context, Singapore and Malaysia are examples for Vietnam to make reference to and summarize their certain experiences. It is not difficult to see that each country will have specific features in its development model. For instance, Singapore's or Malaysia's development government has distinctive pattern of individuals as leaders for a long time (i.e famous government leaders as Lee Kuan Yew, Mathathir Mohamad). Meanwhile this pattern is not clearly seen in Japan. Or the economy development policies based on potentialities or specific advantages, policies with highlights or public administration culture etc are different among nations. The other factors of high political determination, lean organization apparatus, "opener" and more friendly administration establishment etc are those that need further studies as they are indispensable in every government or nation which aims at sustainable development.

\section{Conclusion}

Globalization and international integration require Governments to obtain pure transparency and integrity. For developmental government, this requirement is even more focused as all of the activities of the government are necessarily not only normal openness but also pure transparent, along which accountabilities, especially those of top managers are heightened. There is a focus on improving satisfaction of individual, organizations and enterprises for the government. Administrative procedures must be lean without incurring problems and harassment. Information access right for national administrative management should be improved etc. Especially, corruption and group interests will be quickly erased to promote agreement and support of the society for the Government policies. Effectiveness of specialized bodies on anti-corruption and strong determination to address corruption drastically as stipulated in the law in timely and satisfactory manner needs to be prioritized to consolidate and strengthen.

It can be affirmed that, in order to learn from international experience on establishing developmental government requires caution and prudence as there is no single model for every country. Moreover, dissimilar political regimes are to be considered. Established and maintained developmental governments are not yet optimal but there are still unsoundness, challenges or even conflicts in those countries not yet fully exposed. As a result, learning from their experiences needs a wide viewpoint from different angles before withdrawing references to seize opportunities, overcome challenges and avoidable shortcomings.

Establishment and maintain developmental government is an inevitable requirement in Vietnam currently to build a government which is more transparent and stronger toward service administration and truly rule-of-law socialist State of the people, by the people and for the people.

\section{References}

1. ADB. Serving and Maintaining: Public administration improvement in a competitive world (National Political Publishing House, Hanoi, 2003)

2. Meredith Woo-Cumings, The Developmental State (Cornell University Press, Cornell, CA, 1999) 
3. Pham Ngoc Thanh, Innovation on leading and management culture in Vietnam (National Political Publishing House, Hanoi, 2013)

4. Ngo Duc Huy, Nguyen Thi Thanh Dung, Social Science Information Bulletin 11, 3-9 (2015)

5. Nguyen Trong Binh, Bulletin of Political Reasoning and Science Information 6, 64-72 (2017)

6. Vu Cong Giao, Legislation Studies Bulletin 17, 8-19 (2017)

7. Tran Thi Quang Hong, Legislation Studies Bulletin 9, 9-17 (2017)

8. Le Quoc Ly, Political Reasoning Bulletin 4, 11-15 (2017)

9. Le Minh Quan, Political Reasoning Bulletin 8 (2017)

10. Mai Van Thang, Developmental State in the context of current culture and politics of Vietnam. Speech at Symposium Developmental State: Theoretical and Practical conditions in Vietnam and worldwide (Hanoi National University, 2017)

11. Do Duc Tho et al., Theme: Develop a strong global innovation system. Printed in Innovation Economy - the competition to gain advantages in the global scope (National Political Publishing House, Hanoi, 2017) 